\title{
Retention of First Year Students in Canadian Institutes of Engineering and Technology: Affecting Factors and Solutions.
}

\author{
Dr. Rafiqul Islam \\ Dept. of Industrial \& Engineering Technology \\ Northwestern State University \\ Natchitoches, LA 71497. \\ Tel: 318-357-5352 \\ Fax:318-357-6145
}

Email: islamr@nsula.edu

\begin{abstract}
The freshman year is critical for both academic success and retention of students in engineering and technology programs. There has been argument of considering student completion rates as a fundamental measure of success of the student or the institution. But the drop out of a student after first year of education is considered overwhelmly by the education community as a terrible waste of human and financial resources. Also because of phenomenon growth, sweeping changes of technologies and the economic globalization it is rewarding to focus our whole hearted effort to retention. That is why, the author has identified the related most important factors such as student orientation and motivation, curriculum innovation and integration, underrepresented groups, human interface issues and employment opportunities.
\end{abstract}

There must be a well-established coordination between the institution's responds for adjusting their programs and services and the today's students' expectation. First year seminar course that provides the basis for cohesive learning is useful. The author will demonstrate the effect of changing the sequence of courses on retention in electrical engineering technology program in a Canadian institution. The underrepresented groups specially the women whom represent nearly fifty percent of the population will be motivated to enroll and finish the program by understanding that the carriers in these fields are exciting, rewarding and accessible. Human interface issues such as active learning and teaming will be presented. The overall job prospects along with ever lasting demands in some special categories will be pointed out to the employment concern students.

The goal of this study is to retain even one student out of the dropouts by individual institution. This modest achievement will not only make a difference in his/her life but 
also significantly affect the number of graduated students, which the society needs and deserves.

\section{Introduction}

In the recent years retention has received an extraordinary amount of attention as it has become a significant issue although the aggregate retention rates in the United States have remained surprisingly constant over the past hundred years $(1880-1980)^{1,2}$. It is important to mention here that there is no substantial difference between the USA and Canada in terms of published studies dealing with retention of traditional college age students $^{2}$. The Roman poet Manlius wrote' The end depends on beginning'. So the first year is being considered as the make or break of the students' success ${ }^{3}$. The current trend across the country is to enhance freshman experience in the hope of improving student attitudes and retaining students beyond first year. There is an on-going decline in freshman engineering and technology enrollments since mid-1980's ${ }^{4}$. The number of students with first year engineering and technology majors in four-year institutions has declined by about 26 percent over the past fifteen years ${ }^{5}$. This trend has further underscored the attrition problem. So it is very important to investigate interventions to increase retention. It is also established that the monumental growth and sweeping changes in engineering and technology will keep on shaping our society throughout the 21 st century as we have already entered into economic globalization. This is why; the combined problems of enrollment and retention are not only the concern of engineering and technology administrators but also the industry people. Indeed, the demand for engineering and technology graduates is expected to rise gradually in foreseeable future as the industries are increasing seeking graduates with appropriate background and training in different conventional and emerging fields of engineering and technology ${ }^{4}$. The primary goal of the academic institutions in North America is to provide the workforce of the future. But according to a researcher for a taxpayers group the University of Wisconsin like most Universities in the United States is actually doing less each year, not more to develop the work force ${ }^{6}$. As our students are moving from natural sciences to social sciences, we are producing fewer graduates who can contribute to economic development especially in the areas of engineering and technology. This trend has started after 1985 and by 1997 the institutions have granted tens of thousands fewer degrees in business, engineering and computer science than in social sciences especially in psychology ${ }^{6}$. In this situation recruitment is not just enough, we must retain students as well. The idea is to provide all kinds of support in first year, which could be their most critical year in college ${ }^{7}$. The hope is that if they survive first year of the program they will probably make it through graduation. This is why, the author thinks that it is vital to focus on retention for the health of the technological society in which we are living. Retention is studied from several perspectives as mentioned earlier with more emphasis on curriculum innovations and integration and underrepresented groups.

\section{Curriculum Innovation and Integration}

Curriculum development and implementation is an on-going process in engineering and 
technology programs. DeVry Institute of Technology in its USA and Canadian campuses has changed the sequence of courses in its first year curriculum in electronic engineering technology program during middle of 90's. Instead of starting with DC circuit analysis course (which is a normal trend in most other Universities and colleges) the students need to start with digital circuits course (ET-122). There are several purposes of offering this course in the first semester. First, it exposes students from the very beginning of their course study to both analog and digital electronics. This allows the students to analyze digital blocks which are made of ICs at the functional levels. The mathematics needed for such analysis is significantly less cumbersome as compared to that needed for DC and $\mathrm{AC}$ circuit analysis. This will motivate students to become more interested in electronics because many of them become disenchanted after discovering that the first electronics course (usually circuit analysis) are mostly treatises on mathematics exercises. Second, first term placement allows more math-intensive DC circuit analysis course to be taught in a later term, after students have acquired college algebra proficiency. This also speeds up the students' learning in all circuit analysis courses. Third, more and more applications circuits are fabricated in LSI, VLSI and USLI with rapid advancement of electronic technology. Moreover, since most electronic circuits in computer, control and communications systems are digital, more attention should be devoted to digital courses than circuit analysis courses. Fourth, to examine it's effect on the retention of students in the electronic engineering technology program.

Since the students have no prior electronic knowledge, concepts such as voltage, current and resistance are developed in the course. Simple Ohm's law problems and the supporting mathematical concepts (power of ten, engineering and scientific notation) are included to facilitate basic understanding of logic devices. The associated basic laboratory course also included discussions of basics of electronic test equipments.

The result of a survey among 24 students in electronic engineering technology after the completion of first year during 1988-89 calendar year is illustrated in figure 1 given below:

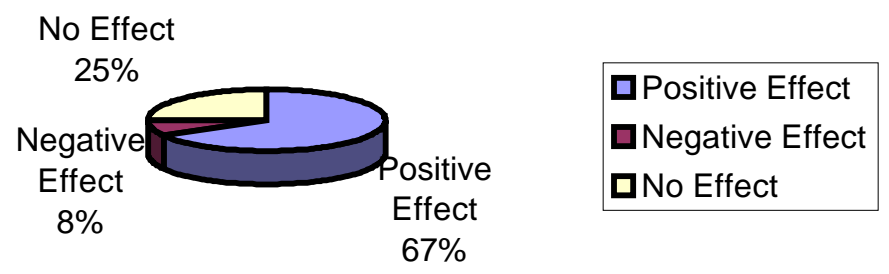

Figure 1 Distribution of effects on retention 
The result shows a mixed reaction among the students towards their decision to continue with electronic engineering technology major. But it is significant to note that out of this pool of students more students have responded positively than negatively. In the face of declining enrollment and completion of the degree and diploma programs in engineering and technology throughout North America this change is definitely working for an easy transition and adaptation for engineering and technology majors. DeVry still continues this change in sequence considering it an important factor in boosting its retention.

Traditionally most freshman level mathematics, chemistry and physics courses are taught in isolation from each other. The students fail to understand the connection between subjects as they respond by 'compartmentalizing' their technical knowledge. Again the 'cafeteria' style process of selecting courses further compounds the problem. Most engineering programs view the output of the freshman math and science courses as the input into their courses. Consequently, there is relatively little interaction on the education level between engineering professors and their colleagues in the math and science department. The professors in engineering, science and mathematics found that the engineering students often compartmentalize their knowledge of basic science and mathematics as they do not consider them as engineering. Often the students in the traditional undergraduate study may fail completely to recognize the same material presented differently. For example, a student, introduced to integration in their calculus course may have hard time understanding it in the next semester physics course. As a result, most engineering and technology programs lose many students during the freshman year. In order to solve the problem, the University of Alabama has presented an integrated set of four freshman year courses for all engineering majors during 1994-95 academic year. The University has integrated the curriculum materials across chemistry, engineering, mathematics and physics in the hope of improving student understanding of selected materials through reinforcement, motivation and additional exposure. Material common to two or more courses is introduced simultaneously to enhance students' understanding. For example, the introduction of the derivative in the calculus course is paralleled with the use of derivatives to solve simple mechanics type of problem in physics. The engineering course offered several three-week, open-ended design problems, which are integrated with the material presented in other three courses. The purpose was to motivate students by showing them how engineering actually uses the fundamental knowledge of basic science and mathematics to solve the real world problems. The overall goal has been for students to understand that mathematics, chemistry and physics are not simply hurdles that they must leap to enter engineering, but are the foundations upon which engineering is built. Several other Universities along with the University of Alabama have observed positive responses from students and have refined the program for delivery to a much larger group of students ${ }^{8}$.

It is also necessary to provide more help for the students who take longer time to fit themselves with the system. SCATE (South Carolina Advanced Technological Education) center's curruculum for pre engineering technology and first-year engineering technology (ET) students was the cornerstone of the center's strategy to retain and graduate more students. This curriculum was designed to prepare slightly-under prepared (C) 2002, American Society of Engineering Education" 
students to be successful in engineering technology (ET) majors. The students benefited from the use of an integrated, problem-based curriculum. Eight South Carolina technical colleges implemented the SCATE curriculum for the students. The retention rate increased from $71 \%$ to $94 \%$ in fall of 1988 and averaged $88 \%$ in the fall of $1999^{9}$.

\section{Orientation \& Motivation}

Orientation and motivation efforts should be rigorous and continuos towards effectiveness of retention. The goal is to implement a campus-wise retention strategy to help students succeed and persevere. As the student's needs and expectations are changing the colleges and Universities must continue to adjust their programs and services to recruit and retain today's students. Basic personal needs must be acknowledged and addressed by the institutions. Overpromising/underdelivering by the institutions will result in inflated student expectations and lower satisfaction. The higher the cost for attending an institution, the more its students will expect ${ }^{10}$. It is very much traditional for the institution to depend on spring visits and summer orientation to introduce newcomers to the campus. But increasingly many institutions feel that a week or less to learn everything about the new school before starting in the fall is not good enough. That is why, the institutions are adding on-line chat rooms where incoming students can meet virtually other new students, current students and in some cases faculty and staff as well. A virtual open house has been held by DePaul University for six hours during spring, 2000. There have been three times as many students as attendance at a conventional open house ${ }^{11}$. The University's web page at www.depaul.edu was linked to more than 20 live chat rooms. DePaul was overwhelmed by the success of this event and has decided to continue in next semester. The current students are considered as the ambassadors for the school. They take part in answering questions for cyberspace visitors along with faculty and staff. This helps the new students to acquire a sense of community and connection with other people. Virtual social club can also be of greatest help as it displays student's options on everything from housing choices to general social life. Usually the connection with current student's go far beyond anything the institution provides in official information packets. This definitely establishes an early link to the campus, a sense of belonging. It is obtained from research that earlier a student gains a sense of belonging, the more likely that student will make it through the first year to the second year and on to graduation. During 1999 the University of Saskatchwan has developed a first year experience program in order to increase the first year retention by helping the students to meet both academic and social needs. The students have been provided with classes and mentoring to acquire the academic standards demanded in post secondary studies. At the same time they have been encouraged to get involved in the non-academic life of the University through volunteerism, spots and social activities ${ }^{12}$. Also the strategy of good follow-up with students in academic difficulties pays off. The colleges and Universities should seek out information (feedback) from students about their experience to ensure that they are making most of their time while they are in the process. Also they can determine if there is a way to make their time even more satisfying. 
First year seminars have entered into the higher education main stream. About $71 \%$ of more than 4000 accredited US campuses offer such programs. About $85 \%$ of freshmen take them and the survival rate of the students who take the courses is $3 \%$ to $10 \%$ better than that of the students who do not. These courses often provide the basis for cohesive learning communities, which spark intellectual confidence among their participants ${ }^{13}$.

\section{Underrepresented Groups}

As women constitute $50 \%$ of the population, an increase in women choosing careers in these fields could help curb the predicted shortfall in the professional workplace. In the United States the job growth rate for the scientists and engineers should be twice the rate of rest of the economy around 2000s. Women and minorities must be the other sources in the engineering workforce rather than the traditional white male. However, young women are not choosing technical careers at the same rate as young men. The motivation must start in high school level, as drop-off in the study of technical careers among young women is extremely steep from high school through college. They should be persued with the programs that support and encourage them to choose challenging career options in engineering and architecture ${ }^{14}$. The WISE (Woman in Science and Technology) program in Newfoundland and Labrodor during 1988 has placed 320 grade eleven female students in paid, eight-week summer research positions in Memorial University. They have enjoyed hands-on exposure to work, weekly tours and personal interactions with scientist and engineers. The aim was to demonstrate that careers in these fields are interesting, rewarding and accessible as well as to build self-confidence and to provide support network for the students. Other activities are organized to enable enough students to socialize with each other and other mentors and to be exposed to wide variety of career options. The WISE participants have conveyed very clear and powerful outcomes of the summer program which centered on education/career related advantages and on personal growth $^{15}$. In secondary school, the boys and girls alike should be encouraged to keep their options open by selecting mathematics and science courses especially physics, chemistry and advanced mathematics, along with home economics and technology/shop courses.

Empowering girls and young women to believe in themselves is another key objective of any program.

Though the enrollment of women in Canadian undergraduate engineering programs has increased steadily from 1989 to 1995 to about 20\%, their enrollment in mechanical, computer and electrical engineering is low (9-12 percent). We must increase the enrollment in the later cluster as many of today's well-paying jobs are in these fields ${ }^{16}$. A closed loop co-ordination which includes all elements of education system especially parents and teachers can help remove obstacles and barriers. The women faculties in engineering have very positive effect on the retention of female students. The environment in the campus is also a decisive factor and issues such as accommodating education and family (childcare). The elimination of harassment, sexism, and discrimination will have a positive impact on the retention of women who have chosen to be engineers. Active participation of woman is also desired to make sure that their perspectives and needs are adequately reflected in the governance of the profession. The 
women student enrollment and retention are even more important when there is a projected decline in male high school students. Also the 'chilly campus climate' has identified the behavior that causes women to lose confidence, lower their academic goals and limit their career choices. The studies conducted in the US and Canada found similarities. The minority students are also considered as a vital source of graduates needed for engineering workforce. All the Universities and colleges should provide a sincere push to retain the minority students who have decided to pursue an engineering and technology education. It will enhance diversity in the work place as well as competitiveness in an increasingly diverse consumer market. From the corporation points of view it is established that diversity in the work place enhances creative thinking, improves decision making, increases worker retention, recruitment and productivity and decreases legal vulnerability in today's market place.

\section{Human Interface Issues}

Human interface issues, such as active learning and teaming have been shown by many educational researchers to significantly improve learning of many students. The active learning strategies that have been used include short in class recitation exercises, fiveminute 'brainstorming' exercises etc. Assignment of short report writing on related topics or any other collaborative writing assignments of informal and formal reports will encourage students to gather information from recent publications, journals and Internet home pages. If time permits the information and knowledge acquired by one group can be shared to the rest of the class through short presentation. Not only will such experience prepare the students for industry (ultimate goal), it will give them opportunities for positive human relations and goal-oriented behavior.

An innovative approach to conduct laboratory courses in an electronics sequence at the University of North Dakota has provided the students with many opportunities for leadership, communication, teamwork, planning and originality. In this approach the students have worked in three or four member teams (known as lead groups) and have developed their new experiments under the instructor's guidance instead of performing the experiments that are predefined by the instructor. Each lead group has been responsible for developing two laboratory experiments on topics that are pertinent to the materials being covered in the concurrent lecture class. The instructor has been involved with topic selection only. The lead groups then have distributed the lab exercises to the remainder of the class prior to the schedule lab sessions. The lead groups have been assigned the responsibility of administrating labs (acting as a mentor) as their classmates have performed the lab exercises ${ }^{17}$.

The "community building model" promotes a high level of collaborative learning through various mechanisms including clustering students in courses and providing student study centers. The center theme is collaborating learning which greatly increases the student learning through deeper understanding of course materials. It not only improves academic performance but also improves retention and student satisfaction with improved oral communication skills and higher student self esteem. With this model several institutions 
have produced improved results especially for the minority students. The University of Wyoming has promoted this collaborative learning by clustering students in a living environment offered by the housing department on campus. They have started on campus housing for all engineering students living on the engineering floor during fall 1995 semester. The success of this living arrangement is indicated not only by higher retention rate among engineering students but also by the ever-increasing number of students to be there ${ }^{18}$.

\section{Employment Opportunities}

The goal of the colleges and Universities is to prepare the technical workforce for immediate employment in a wide variety of industries and businesses. In today's education environment the graduates are coping with a combination of high debt and an uncertain job market. Evidence from the USA shows that reducing the debt of first-year students from low-income backgrounds significantly increases college retention ${ }^{19}$. The occupations are influenced by the ups and downs of the economy as some are more sensitive to economic fluctuations than others. Also the sectorial unemployment rate varies relative to overall unemployment level. Statistics Canada regularly produces unemployment data broke down by various demographic variations as well as by occupations and industries. In an excellent article 'unemployment-occupation makes a difference' the unemployment rates of different occupations are tracked over time to see the rate of growth of employment in a recovery time and a decrease of employment in recessionary times ${ }^{19}$. The labor market and the prevailing unemployment rates in particular affect attrition. Students are more persistent when they perceive that holding a diploma/degree will give them a competitive edge to find employment in a difficult time. The information about job markets and realistic employment prospects must be an ongoing service to the students. They may realize their long-term benefit from completing the program by achieving increased marketability, flexibility and income potential throughout their working life. The students should also be notified that recession does not last for long time specifically in the engineering and technology fields. The recession of 1991 and the boom for the last decade (1991-2001) have proved it. There will be no shortage of jobs in the global market in these fields. Thus the clear picture about prospects of jobs in these fields will help students to hang around until completion of diploma or degree programs.

\section{Conclusion}

Retaining students is an important goal for colleges and Universities. Retention is not only just for the student's sake, who will learn much of their critical thinking and communications skills throughout their campus life, but also for the sake of the colleges and Universities which spend more to recruit as well as to keep them. Tools should be there to identify 'at risk' students and intervention strategies could be developed and implemented at the first available time, even prior to actual enrollment and continued throughout the semester or student's college life. Follow up with students in academic difficulty will address this concern. A percentage of first year students will have their 
educational goals and commitments challenged. Care must be taken to catch these students and increase their chances of staying. The on-line chat rooms can provide a really good impression or an erroneous impression. But it is worth to take a risk. The fields of engineering and technology can only become more diverse and broadly based as relatively untouched population such as women and minorities are involved. It is necessary to create unique opportunity to accelerate progress on the participation of women in science and engineering programs. Otherwise it may decline, if the obstracles, that are more systematic in nature and embedded in culture, the curriculum and teaching style, are not removed. We have the responsibility to convey the message that completion of a diploma or degree program brings benefits such as increased employability and higher potential lifetime earnings. Increased awareness of market conditions will reduce unrealistic employment expectations and help students establish long term goals.

The result of a survey identifies the positive impact on students towards retention when the curriculum sequence is changed in electronic engineering technology program at DeVry campus in Calgary, Canada. It is not clear yet whether this change in sequence has caused the students to continue who would not have otherwise. So, further studies in different campuses in DeVry are sugested. Curriculum integration can be incorporated along with this change of sequence of courses to enhance the overall retention. The author's goal to help the colleges and Universities to retain even one more student out of the pool of dropouts can be achived by following the examples presented here.

\section{Reference}

1. Cheryl, Moller-Wong, Arvid Edie, 'An Engineering Student Retention Study' Journal of engineering education, January 1997.

2. Gerlinde Sarkar, 'Factor Affecting Retention of First-Year students in a Canadian technical Institute of Applied Science and Technology SIAST Retention Study, 1993.

3. Time Magazine, College of the year' 2001 (Web Site)

4. Mary Besterfield-Sacre, Cynthia J. Atman, Larry J. Sherman, 'Characteristics of First-year Engineering Students: Models for Determining Student Attrition in Engineering' Journal of Engineering Education, Apri1, 1997.

5. Raymond B. Landis, 'Improving Engineering Guidance: Introduction to Engineering for High School Teachers and counselors', ASEE Annual Conference Proceedings at Charlotte, NC, June 1999.

6. William Wresch, 'Colleges are Contributing Less, Not More, to Economic Development' ASEE Prison, January 2002 pp 76.

7. Virendra V. Sherma, Judith Grimes and Huiming Wang, 'Exploring the Recruiting and Retention Paradigm: What Works and What does not' ASEE Annual Conference at Charlotte, NC, June, 1999.

8. Joey Parker, David Codes etc., 'Curriculum Integration in the Freshman Year at the University of Alabama-Foundation Coalition Program', ASEE/IEEE Frontiers in Education, 1995.

9. South Carolina ATE Center of Excellence, 'Executive Summary', March 2000.

10. Noel Levitz, An USA Group Company, 'National Report Reveals Shifts in 
Students' Expectations and Colleges Responses'.

11. Chicago Sun Times, ' On-line Chat Rooms Help Orient Students' Section

Education, August 1, 2000.

12. The University of Saskatchewan, 'Welcoming Students, A Helping Hand for

First-Year Students' Annual Report, 1999-2000.

13. Time Media Kit, 'Colleges of the Year, Welcoming Freshmen' Time Web

Site.

14. Camillie F. DeYoung and Suzanne D. Bilbeisi, 'Reaching Engineering and

Architecture Career Heights: College Program To Interest Young Women in Engineering, Architecture and technology' ASEE Annual Conference

Proceedings at Charlotte, NC, June, 1999.

15. Carolyn J. Emerson and Faye Murrin, 'I know I can be Whatever I Choose:

Outcomes of a Summer Job Experience, Presented at the Women at the workplace: Achieving Harmony Conference', Vancouver, B.C., May 22, 1988.

16. Monique Frize, Claire Deschenes, Elizabet Cannon etc., 'A Unique National

Project to Increase the Participation of Women in Science and Engineering.

' Presented at the Engineering Foundation Conference on Women in engineering, Mont Tremblant, July 14-18, 1998.

17. Arnold F. Johnson, 'Students Designing, Mentoring and Learning in a Laboratory Environment' ASEE Annual Conference Proceedings, at Charlotte, NC, June, 1999.

18. Salley Steadman and David Whitman, 'Residential Innovations for Engineering Students', ASEE Annual Conference Proceedings, at Charlotte, NC, June, 1999.

19. Gower, 'Perspective', winter 1991, Statistics Canada.

Biography

DR. RAFIQUL ISLAM is a faculty of the Northwestern State University at Natchitoches, Louisiana in the department of industrial and engineering technology. He had been on the faculty of the DeVry Institute of Technology, Calgary, Alberta, Canada, for five years. He also taught for four years at the West Coast University, Los Angeles, California. He has ten years of working experience in the areas of communications and computer applications in power and control systems. His areas of interest include cellular and PCS phones, microwave and satellite systems, fiber optics and wireline and wireless LANs and WANs.

"Proceedings of the 2002 American Society for Engineering Education Annual Conference \& Exposition Copyright (C) 2002, American Society of Engineering Education" 